\title{
Diallyl sulfide protects against dilated cardiomyopathy via inhibition of oxidative stress and apoptosis in mice
}

\author{
SHUO PANG ${ }^{1}$, WEI DONG ${ }^{1}$, NING LIU ${ }^{2}$, SHAN GAO $^{1}, \mathrm{JING} \mathrm{LI}^{2}, \mathrm{XU}_{\mathrm{ZHANG}}{ }^{2}, \mathrm{DAN} \mathrm{LU}^{2}$ and LIANFENG ZHANG ${ }^{1}$ \\ ${ }^{1}$ Key Laboratory of Human Disease Comparative Medicine, National Health Commission of China (NHC); \\ ${ }^{2}$ Beijing Engineering Research Center for Experimental Animal Models of Human Diseases, Institute of Laboratory \\ Animal Science, Peking Union Medical College, Chinese Academy of Medical Sciences, Beijing 100021, P.R. China
}

Received June 18, 2021; Accepted August 26, 2021

DOI: $10.3892 / \mathrm{mmr} .2021 .12492$

\begin{abstract}
Cytochrome P450 family 2 subfamily E member 1 (CYP2E1) is a member of the cytochrome P450 enzyme family and catalyzes the metabolism of various substrates. CYP2E1 is upregulated in multiple heart diseases and causes damage mainly via the production of reactive oxygen species (ROS). In mice, increased CYP2E1 expression induces cardiac myocyte apoptosis, and knockdown of endogenous CYP2E1 can attenuate the pathological development of dilated cardiomyopathy (DCM). Nevertheless, targeted inhibition of CYP2E1 via the administration of drugs for the treatment of DCM remains elusive. Therefore, the present study aimed to investigate whether diallyl sulfide (DAS), a competitive inhibitor of CYP2E1, can be used to inhibit the development of the pathological process of DCM and identify its possible mechanism. Here, $\mathrm{cTnT}^{\mathrm{R} 141 \mathrm{~W}}$ transgenic mice, which developed typical DCM phenotypes, were used. Following treatment with DAS for 6 weeks, echocardiography, histological analysis and molecular marker detection were conducted to investigate the DAS-induced improvement on myocardial function and morphology. Biochemical analysis, western blotting and TUNEL assays were used to detected ROS production and myocyte apoptosis. It was found that DAS improved the typical
\end{abstract}

Correspondence to: Professor Dan Lu, Beijing Engineering Research Center for Experimental Animal Models of Human Diseases, Institute of Laboratory Animal Science, Peking Union Medical College, Chinese Academy of Medical Sciences, Building 5, Panjiayuan Nanli, Chaoyang, Beijing 100021, P.R. China

E-mail:1vd@cnilas.org

Professor Lianfeng Zhang, Key Laboratory of Human Disease Comparative Medicine, National Health Commission of China (NHC), Institute of Laboratory Animal Science, Peking Union Medical College, Chinese Academy of Medical Sciences, Building 5, Panjiayuan Nanli, Chaoyang, Beijing 100021, P.R. China

E-mail: zhanglf@cnilas.org

Key words: cytochrome $\mathrm{P} 450$ family 2 subfamily $\mathrm{E}$ member 1, inhibitor of CYP2E1, diallyl sulfide, dilated cardiomyopathy, oxidative stress
DCM phenotypes, including chamber dilation, wall thinning, fibrosis, poor myofibril organization and decreased ventricular blood ejection, as determined using echocardiographic and histopathological analyses. Furthermore, the regulatory mechanisms, including inhibition both of the oxidative stress levels and the mitochondria-dependent apoptosis pathways, were involved in the effects of DAS. In particular, DAS showed advantages in terms of improved chamber dilation and dysfunction in model mice, and the improvement occurred in the early stage of the treatment compared with enalaprilat, an angiotensin-converting enzyme inhibitor that has been widely used in the clinical treatment of DCM and HF. The current results demonstrated that DAS could protect against DCM via inhibition of oxidative stress and apoptosis. These findings also suggest that inhibition of CYP2E1 may be a valuable therapeutic strategy to control the development of heart diseases, especially those associated with CYP2E1 upregulation. Moreover, the development of DAS analogues with lower cytotoxicity and metabolic rate for CYP2E1 may be beneficial.

\section{Introduction}

Cytochrome P450 (CYP) family 2 subfamily E member 1 (CYP2E1) is a member of the CYP family of heme proteins and is expressed in the liver, brain and heart in humans and animals (1-4). The CYP2E1 protein is highly expressed on the mitochondria, Golgi apparatus, endoplasmic reticulum and plasma membrane $(5,6)$. CYP2E1 is a key monooxygenase enzyme involved in the metabolism of several endogenous substrates, as well as hundreds of xenobiotics, obtained from diet and environmental contamination (2,4-6). Compared with other CYP family members, CYP2E1 possesses remarkably high NADPH oxidase activity. Thus, it can catalyze the reaction of NADPH and $\mathrm{O}_{2}$ to generate reactive oxygen species (ROS) $(7,8)$. CYP2E1 is the major enzyme for the production of cellular and mitochondrial ROS and reactive nitrogen species (RNS), which induce tissue damage mainly by damaging cellular and mitochondrial macromolecules, including mitochondrial DNA (9-11).

The expression level of CYP2E1 is upregulated in a wide variety of pathological states and diseases, including obesity, diabetes mellitus, alcoholic liver disease, heart diseases, 
inflammation, Parkinson's disease and cancer (12-17). In view of the expression characteristic of CYP2E1, it has been used as a therapeutic target in drug discovery and already has been applied in preliminarily studies (18). Diallyl sulfide (DAS) is a competitive inhibitor of CYP2E1, which is isolated from garlic $(18,19)$. It has been reported that DAS treatment can recover ethanol-induced pathological changes in the liver by inhibiting CYP2E1-mediated alcohol metabolism and subsequent oxidative stress $(20,21)$. Furthermore, DAS treatment can prevent myocardial systolic dysfunction induced by chronic ethanol exposure (22). Studies of the effects of DAS suggested that CYP2E1 inhibition may have potential effects on the development of diseases characterized with high CYP2E1 expression.

Dilated cardiomyopathy (DCM), characterized by the dilation of the heart chambers and impaired systolic functions, is the most frequent cause of heart transplantation and it is the third most common reason for heart failure (HF) (23). Accumulating evidence has indicated the important role of oxidative stress in the pathophysiology of cardiac remodeling and HF $(24,25)$. Furthermore, it has been shown that CYP2E1 is upregulated in multiple cardiovascular diseases, including DCM, hypertrophic cardiomyopathy (HCM) and ischemia $(4,5,26-32)$. Our previous study revealed that the phenotype of CYP2E1 overexpressing-transgenic mice was similar to that of DCM, and knockdown of endogenous CYP2E1 expression markedly prevented the development of DCM in mice $(4,27)$. In addition, since CYP2E1 is a major source of cellular and mitochondrial ROS/RNS, inhibition of CYP2E1 may improve the pathological development of DCM. The aforementioned studies suggest that inhibition of CYP2E1 may improve the pathological development of DCM and application of CYP2E1 inhibitors may become an effective therapeutic approach; however, to the best of our knowledge, no relevant studies have been reported so far.

Therefore, the present study aimed to investigate whether DAS can be used to inhibit the development of the pathological process of DCM and examined the possible underlying mechanism. For this purpose, $\mathrm{cTnT}^{\mathrm{R} 141 \mathrm{~W}}$ transgenic mice, a mouse model with typical DCM phenotypes, such as decreased survival rate, dilated chambers, thin walls and cardiac dysfunction, which were successfully established in our previous studies $(4,26,27)$, were used. Furthermore, the possible inhibitory mechanism of DAS on development of DCM was also investigated in the present study.

\section{Materials and methods}

Animals. The a-MHC-cTnT ${ }^{\mathrm{R} 141 \mathrm{~W}}$ transgenic mice were generated in the Key Laboratory of Human Disease Comparative Medicine and maintained in a C57BL/6J genetic background in the Key Laboratory of Human Disease Comparative Medicine (Ministry of Health, Peking Union Medical College, Beijing, China), and exhibited DCM phenotypic characteristics consistent with those reported previously (4). A total of 58 4-month-old mice were used, including 40 $\mathrm{cTnT}^{\mathrm{R} 141 \mathrm{~W}}$ transgenic mice and 18 wild-type mice. In total, there were 34 males weighing 28-32 g, and 26 females weighing 22-24 g. All mice were bred in an American Association for Accreditation of Laboratory Animal Care-accredited facility, housed at $21 \pm 2^{\circ} \mathrm{C}$ with $50 \pm 5 \%$ relative humidity under a 12 -h day/night cycle and had free access to food and drinking water. The procedures were approved by the Animal Care and Use Committee at the Institute of Laboratory Animal Science, Peking Union Medical College (approval no. ZLF18004).

Groups and treatment. The 4-month-old male and female $\mathrm{cTnT}^{\mathrm{R} 141 \mathrm{~W}}$ transgenic mice were randomly assigned to treatment groups. DAS (cat. no. A35801; Sigma-Aldrich; Merck $\mathrm{KGaA}$ ) was diluted in corn oil to a final concentration of $80 \mathrm{mg} / \mathrm{ml}$. In the treatment groups, $\mathrm{cTnT}^{\mathrm{R} 141 \mathrm{w}}$ transgenic mice were administered DAS at a dose of $200(\mathrm{n}=12)$ or $400 \mathrm{mg} / \mathrm{kg}$ $(n=10)$ via intraperitoneal injection three times weekly for 6 weeks. A group of $\mathrm{cTnT}^{\mathrm{R} 141 \mathrm{~W}}$ transgenic mice $(\mathrm{n}=9)$ and non-transgenic littermates (NTG; $n=8)$ were treated with corn oil ( $0.1 \mathrm{ml}$ per mouse) as the placebo control and wild-type normal control, respectively. As a commercially available drug control, a group of $\mathrm{cTnT}^{\mathrm{R} 141 \mathrm{~W}}$ transgenic mice were treated with enalaprilat (cat. no. H20010498; Changzhou Pharmaceutical Factory) via intraperitoneal injection three times weekly for 6 weeks, an angiotensin-converting enzyme (ACE) inhibitor that has been widely used in the clinical treatment of DCM and HF $(33,34)$, at a dose of $0.76 \mathrm{mg} / \mathrm{kg}(\mathrm{n}=9)$. The dose of DAS was selected based on previous reports $(35,36)$. Therefore, there were total five groups in this study, including NTG normal control, placebo model control, DAS treatment at high dose $(400 \mathrm{mg} / \mathrm{kg})$, DAS treatment at low dose $(200 \mathrm{mg} / \mathrm{kg})$ and enalaprilat. After the last echocardiograph examination, the animals were euthanasia via cervical dislocation.

Echocardiography. Heart function and structure were analyzed via echocardiography once every 2 weeks during treatment. Briefly, the mice were lightly anesthetized via an intraperitoneal injection of $216 \mathrm{mg} / \mathrm{kg}$ tribromoethanol and then subjected to 2-D guided M-mode echocardiography with a 30-MHz transducer for echocardiographic examination (Vevo770; FUJIFILM VisualSonics Inc.). Measurements of left ventricular (LV) fractional shortening (LVFS), LV ejection fraction (LVEF), LV diameter at end systole (LVESD), LV diameter at end diastole (LVEDD), LV posterior wall at end systole (LVPWS), LV posterior wall at end diastole (LVPWD), LV anterior wall at end systole (LVAWS) and LV anterior wall at end diastole (LVAWD) were based on the analysis of $\geq 10$ separate cardiac cycles.

Histological analysis. For light microscopy, heart tissues were first fixed in $4 \%$ formaldehyde at room temperature for $24 \mathrm{~h}$, embedded in paraffin and cut into $4-\mu \mathrm{m}$ thick sections (4). Heart tissue sections were imaged after $H \& E$ and Masson staining. For H\&E staining, the sections were stained using a Hematoxylin and Eosin Staining kit (cat. no. G1121; Beijing Solarbio Science \& Technology Co., Ltd.). Briefly, paraffin-embedded sections were dewaxed in xylene two times for $10 \mathrm{~min}$ each time at room temperature. The sections were rehydrated in a series of ethanol (100, 95, 85 and $75 \%$ ) for $3 \mathrm{~min}$ per gradient, and for $2 \mathrm{~min}$ in distilled water. Subsequently, the sections were stained with hematoxylin stain for $3 \mathrm{~min}$ at room temperature and washed with distilled water to remove floating colors. The differentiation solution was differentiated for $3 \mathrm{~min}$ and washed with distilled water 
twice, for 2 min each time. The sections were put into eosin dye solution for $2 \mathrm{~min}$, then washed with distilled water for 2-3 sec at room temperature. Then, the sections were proceeded to the dehydrated step through soaking in a series of concentrations of alcohol at room temperature (for 2-3 sec at 75, 85 and $95 \%$, for $1 \mathrm{~min}$ at $100 \%$ ). The sections were then incubated with xylene twice at room temperature (for 1 min each time), followed by sealing in neutral gum and finally observed under the microscope.

For Masson trichrome staining, the sections were incubated in celestine blue solution (cat. no. G1345; Beijing Solarbio Science \& Technology Co., Ltd.) for $5 \mathrm{~min}$ and briefly washed with $\mathrm{H}_{2} \mathrm{O}$. Then, sections were incubated in hemalun solution for $5 \mathrm{~min}$ and in fuchsine acid/ponceau xylidine $(0.5 \%$ fuchsine acid, $1.5 \%$ ponceau xylidine, $1,75 \%$ glacial acetic acid) for 5 min. Subsequent, sections were briefly washed with $\mathrm{H}_{2} \mathrm{O}$ and incubated in phosphomolybdic acid (1\%) for $10 \mathrm{~min}$ and in aniline blue solution (2.5\% anilin blue, $2.5 \%$ glacial acetic acid) for $5 \mathrm{~min}$. Next, they were briefly washed with $\mathrm{H}_{2} \mathrm{O}$ and incubated in acetic acid (1\%) for $1 \mathrm{~min}$. Finally, the sections were briefly incubated in an ascending ethanol series followed by xylol, before they were embedded.

Transmission electron microscopy (TEM). Heart tissues $\left(\sim 2 \mathrm{~mm}^{3}\right)$ from the free wall of the left ventricle were fixed in $2.5 \%$ glutaraldehyde (preparation for $100 \mathrm{ml}$ solution: $50 \mathrm{ml}$ of $0.2 \mathrm{M}$ phosphate buffer, $10 \mathrm{ml}$ of $25 \%$ glutaraldehyde and $40 \mathrm{ml}$ double distilled water) at $4^{\circ} \mathrm{C}$ for $12 \mathrm{~h}$ (4). After washing three times with phosphate solution $(\mathrm{pH}=7.2)$, the samples were fixed in $1 \%$ osmium acid at $4^{\circ} \mathrm{C}$ for $2 \mathrm{~h}$. Dehydration was carried out sequentially with four graded concentrations of ethanol between $50-100 \%$ at room temperature. After epichlorohydrin replacement and epoxy embedding at room temperature, tissue sections were cut on an ultramicrotome. The semi-thin sections (thickness, $900 \mathrm{~nm}$ ) were further stained with an equal mixture of $4 \%$ uranyl acetate and acetone for $30 \mathrm{sec}$ at room temperature, and then in lead citrate for $2 \mathrm{~min}$. The final ultra-thin sections $(90 \mathrm{~nm})$ were analyzed under a JEM-1230 transmission electron microscope (JEOL Ltd.).

Measurement of ROS. After treatment, the mice were sacrificed and total lysates were prepared as previously reported (4). $\mathrm{H}_{2} \mathrm{O}_{2}$, malondialdehyde (MDA; lipid peroxidation) and glutathione (GSH) in heart tissues were measured with relevant assay kits $\left(\mathrm{H}_{2} \mathrm{O}_{2}\right.$ Assay kit, cat. no. ab102500; MDA Assay kit, cat. no. ab118970; GSH/GSSG Ratio Detection Assay kit, cat. no. ab138881; all from Abcam) following the manufacturer's procedures.

For the $\mathrm{H}_{2} \mathrm{O}_{2}$ assay, $10 \mathrm{mg}$ tissue was first washed in cold PBS and homogenized in $500 \mu$ l assay buffer with a Dounce homogenizer sitting on ice. The sample was centrifuged $13,000 \mathrm{x}$ g for $5 \mathrm{~min}$ at $4^{\circ} \mathrm{C}$ at top speed using a microcentrifuge to remove any insoluble material. Finally, the content of $\mathrm{H}_{2} \mathrm{O}_{2}$ in the heart tissue was measured with a microplate reader at excitation/emission $(\mathrm{Ex} / \mathrm{Em})=535 / 587 \mathrm{~nm}$.

For the lipid peroxidation assay, $10 \mathrm{mg}$ tissue was first washed in cold PBS and homogenized in $303 \mu 1$ lysis solution with a Dounce homogenizer sitting on ice. The sample was centrifuged at $13,000 \mathrm{x}$ g for $10 \mathrm{~min}$ at $4^{\circ} \mathrm{C}$ to remove insoluble material. Then, thiobarbituric acid (TBA) reagent was added into the supernatant to generate MDA-TBA adduct. Finally, the absorbance was measured immediately at Ex/Em=532/553 nm.

For the glutathione assay, $10 \mathrm{mg}$ tissue was first washed in cold PBS, then was resuspended in $400 \mu \mathrm{l}$ cold lysis buffer. The samples were homogenized and centrifuged at $13,000 \mathrm{xg}$ for $15 \mathrm{~min}$ at $4^{\circ} \mathrm{C}$ to remove any insoluble material. Next, $50 \mu \mathrm{l} \mathrm{GSH}$ assay mixture was added into each GSH standard or collected sample supernatant. Finally, the absorbance was measured at $\mathrm{Ex} / \mathrm{Em}=490 / 520 \mathrm{~nm}$ with a fluorescence microplate reader.

TUNEL assay. For apoptotic cell staining, paraffin sections of heart tissues were stained using an ApopTag Plus Peroxidase In Situ Apoptosis kit (cat.no. S7101; MilliporeSigma) following the manufacturer's procedures. In briefly, heart tissues were first fixed in $4 \%$ formaldehyde at room temperature for $24 \mathrm{~h}$, embedded in paraffin and cut into $4-\mu \mathrm{m}$ thick sections. The tissue slides were rehydrated and were treated with $25 \mu \mathrm{g} / \mathrm{ml}$ proteinase $\mathrm{K}$ at $37^{\circ} \mathrm{C}$ for $8 \mathrm{~min}$ at room temperature. After washing and incubation with equilibration buffer for $5 \mathrm{~min}$ at room temperature, Tdt was diluted at 1:3.9 with reaction buffer and added to heart sections for $1 \mathrm{~h}$ at $37^{\circ} \mathrm{C}$. After applying stop solution for $10 \mathrm{~min}$ at room temperature, the samples were incubated with anti-digoxigenin peroxidase conjugate at $37^{\circ} \mathrm{C}$ for $30 \mathrm{~min}$. Slides were first treated with a 1:20 dilution of diaminobenzidine (3,3'-diaminobenzidine) substrate for $1 \mathrm{~min}$ at room temperature, then counterstained with hematoxylin (cat. no. G1121; Beijing Solarbio Science \& Technology Co., Ltd.) for $30 \mathrm{sec}$ at room temperature. The sections were proceeded to the dehydrated step through soaking in a series of concentrations of alcohol at room temperature (for 2-3 sec at 75,85 and $95 \%$, for $1 \mathrm{~min}$ at $100 \%$ ). Then, the sections were incubated with xylene twice at room temperature (for $1 \mathrm{~min}$ each time), followed by sealing in neutral gum and finally observed under the microscope. In total, nine visual fields were randomly selected in each group to observe the apoptosis under a light microscope (BX53; Olympus Corporation; magnification, $\mathrm{x} 400)$. The results are expressed as the percentage of apoptotic cells among the total cell population.

Reverse transcription (RT)-PCR. Total RNA was isolated from heart tissues using TRIzol ${ }^{\circledR}$ reagent (cat. no. 15596018; Invitrogen; Thermo Fisher Scientific, Inc.) and were used to synthesize cDNA with a RT kit (cat. no. RR820A; Takara Bio, Inc.) following the manufacturer's procedures. mRNA expression levels of procollagen type III $\alpha 1$ (Col3 $\alpha 1)$ was detected via RT-PCR using GAPDH for normalization under standard conditions. The primers were as follows: Col3 $\alpha 1$ forward, 5'-CTCAAGAGCGGAGAATACTGG-3' and reverse, 5'-CAA TGTCATAGGGTGCGATA-3'; and GAPDH forward, 5'-CAA GGTCATCCATGACAACTTTG-3' and reverse, 5'-GTCCAC CACCCTGTTGCTGTAG-3'.

Western blotting. Heart tissues were homogenized and extracted using lysis buffer [tissue protein extraction reagent (cat. no. 78510); protease inhibitor cocktail (cat. no. 87785); phosphatase inhibitor cocktail (cat. no. 78420); PMSF (100 $\mu \mathrm{M}$; cat. no. 36978; all from Thermo Fisher Scientific, Inc.); 100:1:1:1 ratio for configuration], followed by fractionation using a Mitochondrial/Cytosol Fractionation 
kit (cat. no. ab65320; Abcam) to obtain the cytosolic and mitochondrial fractions. An enhanced BCA protein assay kit (cat. no. P0010; Beyotime Institute of Biotechnology) was used to quantify the protein concentration. The total lysates, cytosolic and mitochondrial fractions $(50 \mu \mathrm{g})$ were separated via $15 \%$ SDS-PAGE and transferred to a nitrocellulose membrane (Immobilon NC; MilliporeSigma). Following blocking in 5\% fat-free milk in TBS-0.1\% Tween-20 (TBST) for $1 \mathrm{~h}$ at room temperature, the membranes were incubated at $4{ }^{\circ} \mathrm{C}$ overnight with primary antibodies targeted against: CYP2E1 (1:500; cat. no. ab28146), cardiac troponin T (1:500; cTnT; cat. no. ab8295), cytochrome $c$ (1:500; cat. no. ab13575), procaspase 3 (1:1,000; cat. no. ab13847), procaspase 9 (1:1,000; cat. no. ab47537; all from Abcam), cleaved (active) caspase 3 (1:500; cat. no. 9507S) and cleaved caspase 9 (1:500; cat. no. 9664S; both from Cell Signaling Technology, Inc.), anti- $\beta$-tubulin $(1: 1,000$; cat. no. ab21058) and anti-voltage dependent anion channel 1 (1:1,000; cat. no. ab14734; both from Abcam) were used. Following washing with TBST, the membranes were incubated with a HRP-conjugated secondary antibody (1:10,000; anti-rabbit $\operatorname{IgG}$, cat. no. ZB-2301 or anti-mouse IgG, cat. no. ZB-2305; ZSGB-BIO, Inc.) at room temperature for $1 \mathrm{~h}$. Primary antibody binding was visualized using a chemiluminescent detection system (Western Blotting Luminal Reagent; Santa Cruz Biotechnology, Inc.) and analyzed using the densitometry function of Quantity One software (version 3.0; Bio-Rad Laboratories, Inc.).

Cell lines and culture. H9c2 cells (National Laboratory Cell Resource Sharing Service Platform) were cultured in DMEM (Thermo Fisher Scientific, Inc.), supplemented with 10\% FBS (Thermo Fisher Scientific, Inc.) and $100 \mathrm{U} / \mathrm{ml}$ penicillin-100 $\mu \mathrm{g} / \mathrm{ml}$ streptomycin (Invitrogen; Thermo Fisher Scientific, Inc.) at $37^{\circ} \mathrm{C}$ with $5 \% \mathrm{CO}_{2}$. Cells were treated with DAS (12 h; $100 \mu \mathrm{mol} / \mathrm{l}$; cat. no. A35801; Sigma-Aldrich; Merck $\mathrm{KGaA}$ ) or isoprenaline hydrochloride (ISO; $12 \mathrm{~h} ; 50 \mu \mathrm{mol} / \mathrm{l}$; cat. no. I5627; Sigma-Aldrich; Merck KGaA) at $37^{\circ} \mathrm{C}$ with $5 \%$ $\mathrm{CO}_{2}$ as required.

Calcein-AM/PI double staining. Cell viability was evaluated using calcein-AM/PI double staining following the manufacturer's instruction (cat. no. C542; Dojindo Laboratories, Inc.). Briefly, H9c2 cells were seeded in 96-well plates in triplicate at a density of $1 \times 10^{4}$ cells $/ 100 \mu \mathrm{l} /$ well with $100 \mu \mathrm{l}$ culture medium and cultured for $24 \mathrm{~h}$. The cells were treated with ISO $(50 \mu \mathrm{mol} / \mathrm{l})$ or DAS $(100 \mu \mathrm{mol} / \mathrm{l})$ for $12 \mathrm{~h}$ at $37^{\circ} \mathrm{C}$ with $5 \% \mathrm{CO}_{2}$ and divided into four groups, including control, ISO, control + DAS and ISO + DAS groups. The cells were then washed twice with PBS and the working solution (PBS: calcein-AM: PI=1,000:1:1) and incubated for $15 \mathrm{~min}$ at $37^{\circ} \mathrm{C}$. Live cells with yellow-green fluorescence and dead cells with red fluorescence (Leica Microsystems $\mathrm{GmbH}$ ) were observed using a fluorescence microscope (magnification, $\mathrm{x} 100)$ at $490 \pm 10 \mathrm{~nm}$ and $545 \mathrm{~nm}$ excitation wavelengths. In total, three images of each well were captured for a total of three replicate wells for counting.

Statistical analysis. All experiments were performed $\geq 3$ times. Statistical analyses were performed using SPSS software (version 19.0; IBM Corp.). The data were analyzed using two-tailed unpaired t-tests and one-way ANOVA followed by Tukey's post hoc analysis. Data are presented as the mean $\pm \mathrm{SD}$. $\mathrm{P}<0.05$ was considered to indicate a statistically significant difference.

\section{Results}

DAS improves cardiac morphology breakage and dysfunction in $c T_{n} T^{R 141 W}$ DCM model mice. Compared with the NTG group, the $\mathrm{cTnT}^{\mathrm{R} 141 \mathrm{~W}}$ transgenic mice showed typical DCM phenotypes, such as dilated chambers, thin walls and cardiac dysfunction. The DCM phenotypes were evidenced by increases in LVESD and LVEDD, and decreases in LVPWS, LVPWD, LVAWS, LVAWD, LVEF and LVFS (Fig. 1A-I; Tables SI-SIII).

Firstly, after 2 weeks of treatment, the early stage of drug intervention, it was found that improvement was already observed in both DAS groups, and echocardiographic parameters in both DAS groups showed an improved inhibition trend compared with that of the enalaprilat group. For example, LVESD decreased by 26.5 and $25.9 \%$ in the DAS high and low dose group, respectively, compared with the placebo model control group $(\mathrm{P}<0.001$; Fig. 1B), while LVESD decreased by $18.9 \%$ in the enalaprilat group compared with the placebo model control group $(\mathrm{P}<0.01$; Fig. 1B). Moreover, LVEF increased by 57.8 and $43.1 \%$ in the DAS high and low dose group, respectively, compared with the placebo model control group $(\mathrm{P}<0.001$; Fig. $1 \mathrm{H})$, while LVEF increased by $35.2 \%$ in the enalaprilat group compared with the placebo model control group $(\mathrm{P}<0.05$; Fig. $1 \mathrm{H})$.

After 6 weeks of treatment, LVESD decreased by $22.4 \%$ in the DAS high dose group $(\mathrm{P}<0.001$; Fig. 1B), while it decreased by $11.1 \%$ in the enalaprilat group $(\mathrm{P}<0.05$; Fig. $1 \mathrm{~B})$ compared with the placebo model control group. There was a significant increase in LVEF in the DAS high dose group compared with the placebo model control group $(\mathrm{P}<0.001$; Fig. $1 \mathrm{H})$, while there was no difference between the enalaprilat group and the placebo model control group ( $\mathrm{P}>0.05$; Fig. 1H). Furthermore, there was a significant increase in LVAWD in the enalaprilat group compared with the DAS high dose group $(\mathrm{P}<0.001$; Fig. 1G). LVPWS increased in both the DAS high dose group and the enalaprilat group compared with the placebo model group ( $\mathrm{P}<0.05$; Fig. 1D), while it showed no significant difference between these two groups $(\mathrm{P}>0.05)$.

In summary, both DAS groups and the enalaprilat group exhibited a significant improvement on DCM phenotypes, as evidenced by changes in cardiac function, chamber size and wall thickness. While each factor has its advantages, DAS exhibited a stronger effect on control of chamber dilation and dysfunction, and the enalaprilat group was more effective at increasing wall thickness. Furthermore, this improvement on morphology and function of model mice occurred earlier in both DAS groups compared with that of the enalaprilat group.

DAS inhibits cardiac pathological development in $c T n T^{R 141 W}$ DCM model mice. After drug treatment, hearts from all five groups were sampled for gross morphology and pathological examinations.

First of all, the protein expression level of CYP2E1 was determined via western blotting after treatment with 
A

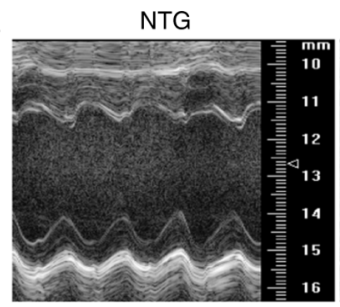

B

$\square$ NTG $\square$ CTnT R141W $\quad 400 \mathrm{mg} / \mathrm{kg}$ DAS
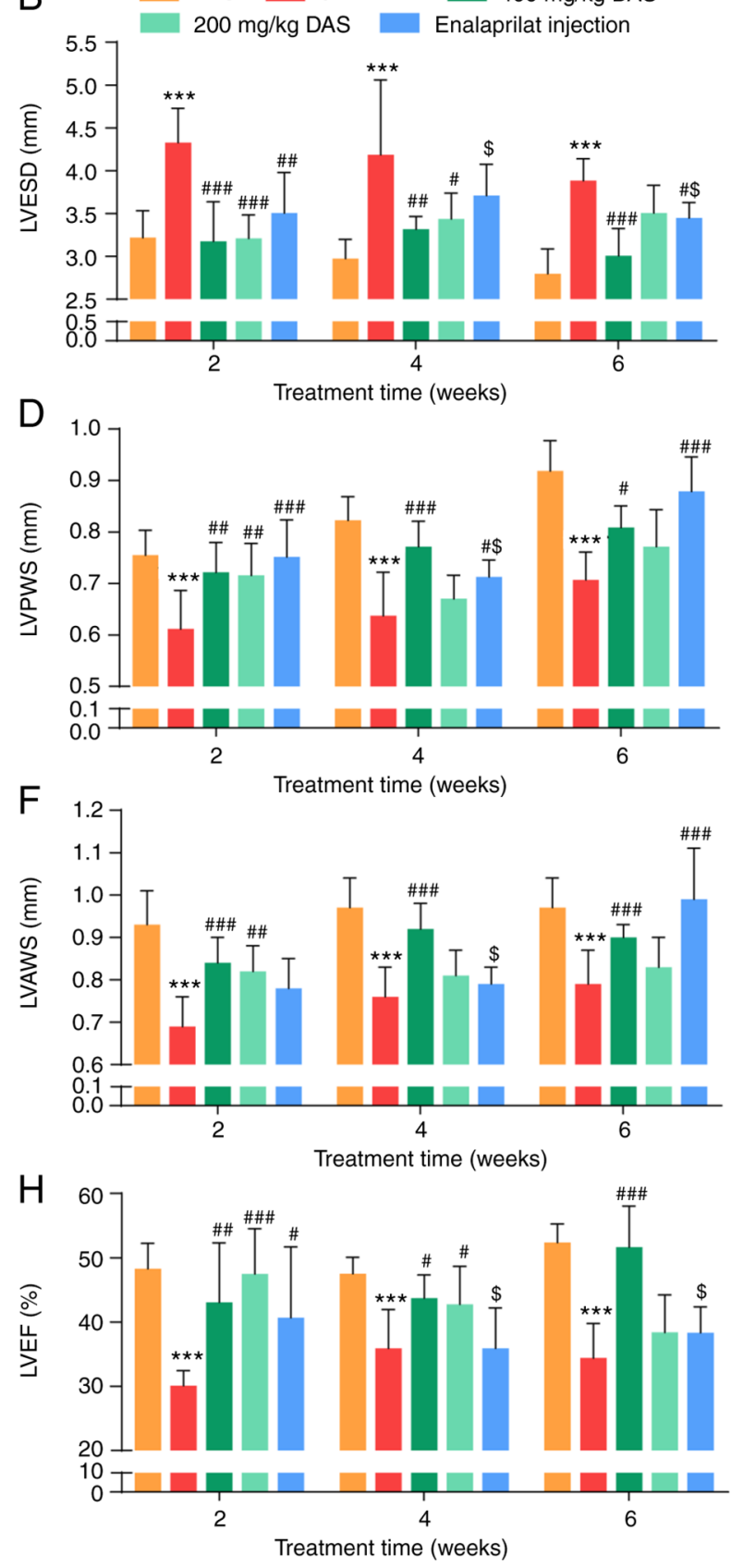

$400 \mathrm{mg} / \mathrm{kg}$ DAS

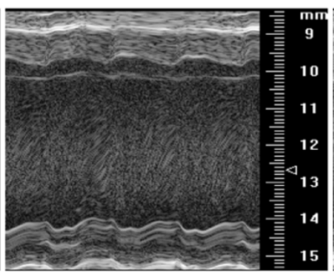

$200 \mathrm{mg} / \mathrm{kg}$ DAS

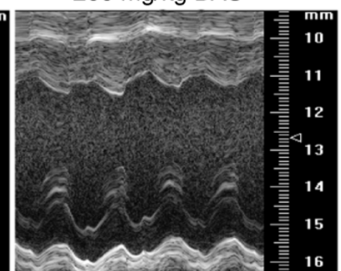

Enalaprilat

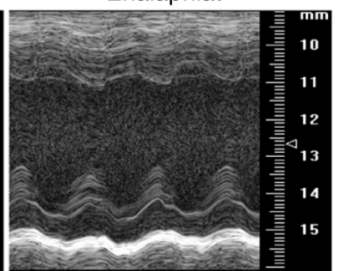

C

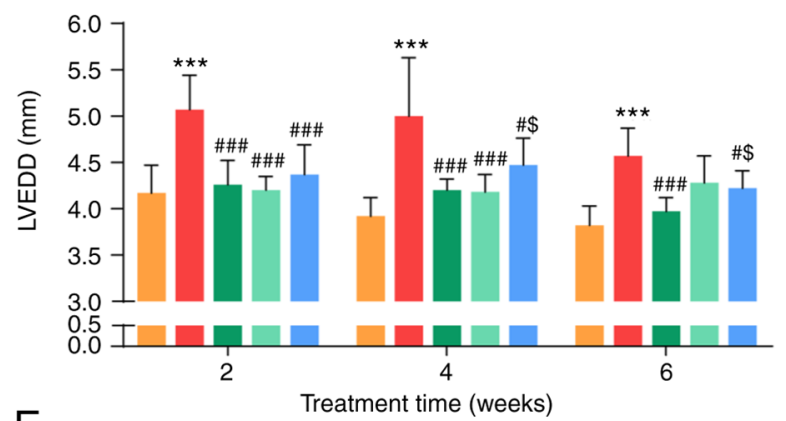

$\mathrm{E}$
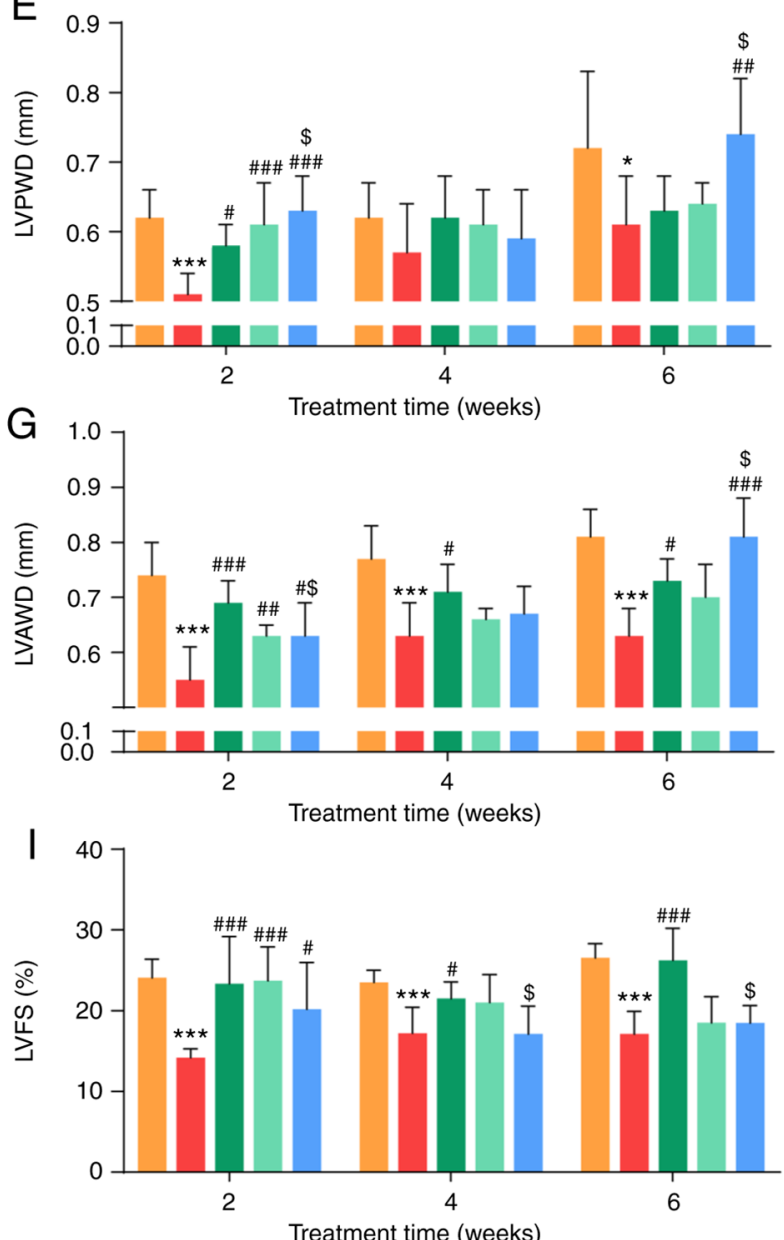

Figure 1. Echocardiographic analysis of cardiac morphology and function. Mice in the five groups were analyzed after 6 weeks of treatment: NTG (wild-type control), $\mathrm{cTnT}^{\mathrm{R} 141 \mathrm{~W}}$ (placebo control), treatment with $400 \mathrm{mg} / \mathrm{kg}$ DAS, treatment with $200 \mathrm{mg} / \mathrm{kg}$ DAS and treatment with enalaprilat (commercially available drug control). (A) Representative M-mode echocardiographic images of the LV long axis. (B) LVESD. (C) LVEDD. (D) LVPWS. (E) LVPWD. (F) LVAWS. (G) LVAWD. (H) LVEF. (I) LVFS. n=7. ${ }^{\mathrm{P}}<0.05,{ }^{* * *} \mathrm{P}<0.001$ vs. NTG group; ${ }^{\#} \mathrm{P}<0.05,{ }^{\# \#} \mathrm{P}<0.01,{ }^{\# \# \#} \mathrm{P}<0.001$ vs. cTnT ${ }^{\mathrm{R} 141 \mathrm{~W}}$ group; ${ }^{\mathrm{S}} \mathrm{P}<0.05 \mathrm{vs} .400 \mathrm{mg} / \mathrm{kg} \mathrm{DAS}$ group. NTG, non-transgenic; LV, left ventricular; LVESD, left ventricular end-systole diameter; LVEDD, left ventricular end-diastole diameter; LVPWS, left ventricular ventricle posterior wall at end systole; LVPWD, left ventricular posterior wall at end diastole; LVAWS, left ventricular anterior wall at end systole; LVAWD, left ventricular anterior wall at end diastole; LVEF, left ventricular ejection fraction; LVFS, left ventricular fractional shortening; DAS, diallyl sulfide.

different doses of DAS. Compared with the placebo model control group, the protein expression level of CYP2E1 in 200 and $400 \mathrm{mg} / \mathrm{kg}$ DAS groups decreased by $35.5 \%$ ( $\mathrm{n}=3$; $\mathrm{P}<0.01)$ and $51.8 \%(\mathrm{n}=3 ; \mathrm{P}<0.001 ;$ Fig. $2 \mathrm{~A}$ and $\mathrm{B})$, respectively. 
Moreover, CYP2E1 protein expression decreased by $35.9 \%$ in the enalaprilat group $(\mathrm{n}=3 ; \mathrm{P}<0.01$; Fig. $2 \mathrm{~A}$ and $\mathrm{B})$. The expression level of cTnT protein was also analyzed. The mutant form of cTnT is the human mutant form that was introduced by the transgenic method, which is the cTnT band at the higher molecular weight in Fig. 2A, and the location of endogenous cTnT proteins in mouse myocardium was slightly lower than that of exogenous mutants. The expression level of the cTnT showed no difference between the three therapeutic groups and the placebo model group (Fig. 2A and C).

The increased heart to body weight ratio of $\mathrm{CTnT}^{\mathrm{R} 141 \mathrm{~W}}$ mice was reversed by DAS treatment to almost the normal level both in the 400 and $200 \mathrm{mg} / \mathrm{kg}$ group (P<0.05; Fig. 2D). DAS treatment significantly improved the chamber dilation, wall thinning and myocyte disarray in $\mathrm{cTnT}^{\mathrm{R} 141 \mathrm{~W}} \mathrm{DCM}$ model mice, as determined via H\&E staining (Fig. 2E and F). Through ultrastructure observation using TEM, it was found that DAS treatment improved the poor myofibril organization, including diffusion, damage and lysis, in $\mathrm{cTnT}^{\mathrm{R} 141 \mathrm{~W}}$ mice (Fig. 2H). Quantitative analysis of the Masson staining and the mRNA expression level of $\mathrm{Col} 3 \alpha 1$ showed that collagen deposition in the interstitial space of $\mathrm{cTnT}^{\mathrm{R} 141 \mathrm{~W}}$ mice was significantly reduced in both DAS and enalaprilat groups compared with the placebo model control group (Fig. $2 \mathrm{G}$ and I-K).

Both DAS and enalaprilat treatment exhibited a favorable therapeutic effect on improving of the destroyed microstructure and ultrastructure of the myocardium in DCM model mice. Moreover, the DAS group exhibited a greater advantage in reducing index of heart to body weight ratio.

To verify the ameliorative effect of DAS on the pathological phenotype of cardiomyopathy in vitro. Cell experiments were performed, and it was found that DAS could significantly inhibit the increased expression of CYP2E1 induced by ISO treatment in $\mathrm{H} 9 \mathrm{c} 2$ cells, as well as significantly improve the cell death induced by ISO (Fig. S1), which were all consistent with the results in vivo.

DAS reduces oxidative stress level in cTnT ${ }^{R 141 W}$ DCM model mice. CYP2E1 catalyzes the production of ROS even in the absence of substrate, leading to oxidative stress (37). Therefore, $\mathrm{H}_{2} \mathrm{O}_{2}$, MDA and GSH levels were measured as indicators of oxidative stress in all five groups.

$\mathrm{H}_{2} \mathrm{O}_{2}$ and MDA levels were significantly decreased $(\mathrm{P}<0.001$; Fig. 3A and B), while GSH levels were significantly increased $(\mathrm{P}<0.01$ and $\mathrm{P}<0.001$; Fig. $3 \mathrm{C})$ in both 400 and $200 \mathrm{mg} / \mathrm{kg}$ DAS treatment groups compared with those of the placebo model group. Inhibition of the expression of CYP2E1 by DAS resulted in a reversion of the levels of $\mathrm{H}_{2} \mathrm{O}_{2}, \mathrm{MDA}$ and $\mathrm{GSH}$ in the myocardium to almost the normal levels in both the 400 and $200 \mathrm{mg} / \mathrm{kg}$ DAS groups. By contrast, no significant differences in those three indicators were observed in the enalaprilat group compared with the placebo model group $(\mathrm{P}<0.05$; Fig. 3A-C).

Therefore, inhibition of oxidative stress level is one of the possible underlying mechanisms of DAS, rather than enalaprilat, that is involved in the protection against the pathological process of DCM.

DAS inhibits mitochondrial pathways of apoptosis in $c T n T^{R 141 W}$ DCM model mice. The induction of CYP2E1 causes cytochrome $c$ release and activation of the mitochondrial apoptosis pathway in the heart in $\mathrm{cTnT}^{\mathrm{R} 141 \mathrm{~W}}$ DCM model mice (4).

In both DAS groups, the increased release of cytochrome $c$ in $\mathrm{cTnT}^{\mathrm{R} 141 \mathrm{~W}} \mathrm{DCM}$ model mice almost reached those of normal levels $(\mathrm{P}<0.05$; Fig. $4 \mathrm{~A}$ and $\mathrm{B})$. The activation of caspase 9 was decreased by $66.6 \%(\mathrm{P}<0.001)$ and $66.9 \%(\mathrm{P}<0.001$; Fig. 4A and C) in the 400 and $200 \mathrm{mg} / \mathrm{kg}$ DAS groups, respectively, compared with the placebo model group. The activation of caspase 3 was decreased by $65.1 \%(\mathrm{P}<0.001)$ and $62.7 \%$ $(\mathrm{P}<0.001$; Fig. 4A and D) in the 400 and $200 \mathrm{mg} / \mathrm{kg}$ DAS groups, respectively, compared with the placebo model group.

The release of cytochrome $c$ from the mitochondria to the cytoplasm triggers the apoptosis of cardiac myocytes in $\mathrm{cTnT}^{\mathrm{R} 141 \mathrm{~W}}$ model mice $(38,39)$. It was determined that there were 69.3 and $64.7 \%$ decreases in proportion of apoptotic cells in the $400(\mathrm{P}<0.05)$ and $200 \mathrm{mg} / \mathrm{kg}$ groups $(\mathrm{P}<0.05$; Fig. 4E and F), respectively, compared with the placebo model group. Furthermore, DAS and enalaprilat exhibited no difference in apoptosis inhibition.

Therefore, inhibition of the mitochondrial apoptosis pathway is one of the possible mechanisms of DAS that is involved in the protection against the pathological process of DCM.

\section{Discussion}

CYP2E1 is an inducible gene that is upregulated under multiple conditions, such as fasting and nutrition intake, as well as in a wide variety of pathophysiological states (2,12-17). In addition to metabolizing endogenous substrates and xenobiotics, CYP2E1 is the main source of cellular ROS, and its NADPH oxidase activity is higher than that of other CYP family members (9-11).

Our previous studies revealed that the expression level of CYP2E1 was increased in multiple mouse models of heart disease, including those of DCM and HCM, and the possible mechanism of upregulation of CYP2E1 expression were examined, in which it was found that Myc was upregulated under pathological stimulus and binds to the CYP2E1 promoter to activate its transcription $(26,27)$. Furthermore, it was determined that the increase of CYP2E1 expression induced cardiac myocyte apoptosis via mitochondrial pathways, and knockdown of endogenous of CYP2E1 expression using small interfering RNA could attenuate the pathological development of DCM in CTnT $^{\mathrm{R} 141 \mathrm{~W}}$ mice (4).

Therefore, in the present study, DAS, a selective inhibitor of CYP2E1, was used to treat $\mathrm{cTnT}^{\mathrm{R} 141 \mathrm{~W}}$ DCM model mice, and to observe whether DAS can be used to inhibit the development of the pathological process of DCM and its possible mechanism.

DAS is an organosulfur compound derived from the metabolism of allicin and has anti-cancer properties (40). DAS inhibits the activity of CYP2E1 and thus has attracted attention as a potential therapeutic or prophylactic agent $(41,42)$. DAS treatment has been applied in several diseases. For instance, DAS treatment can attenuate the pathogenesis of diseases associated with CYP2E1 upregulation in animal models, such as alcoholic liver disease, nonalcoholic steatohepatitis, diabetes and alcoholic cardiomyopathy (18,43-46). At present, to the best of our knowledge, the use of DAS in treating DCM animal models to observe its therapeutic effects had not been previously reported. 

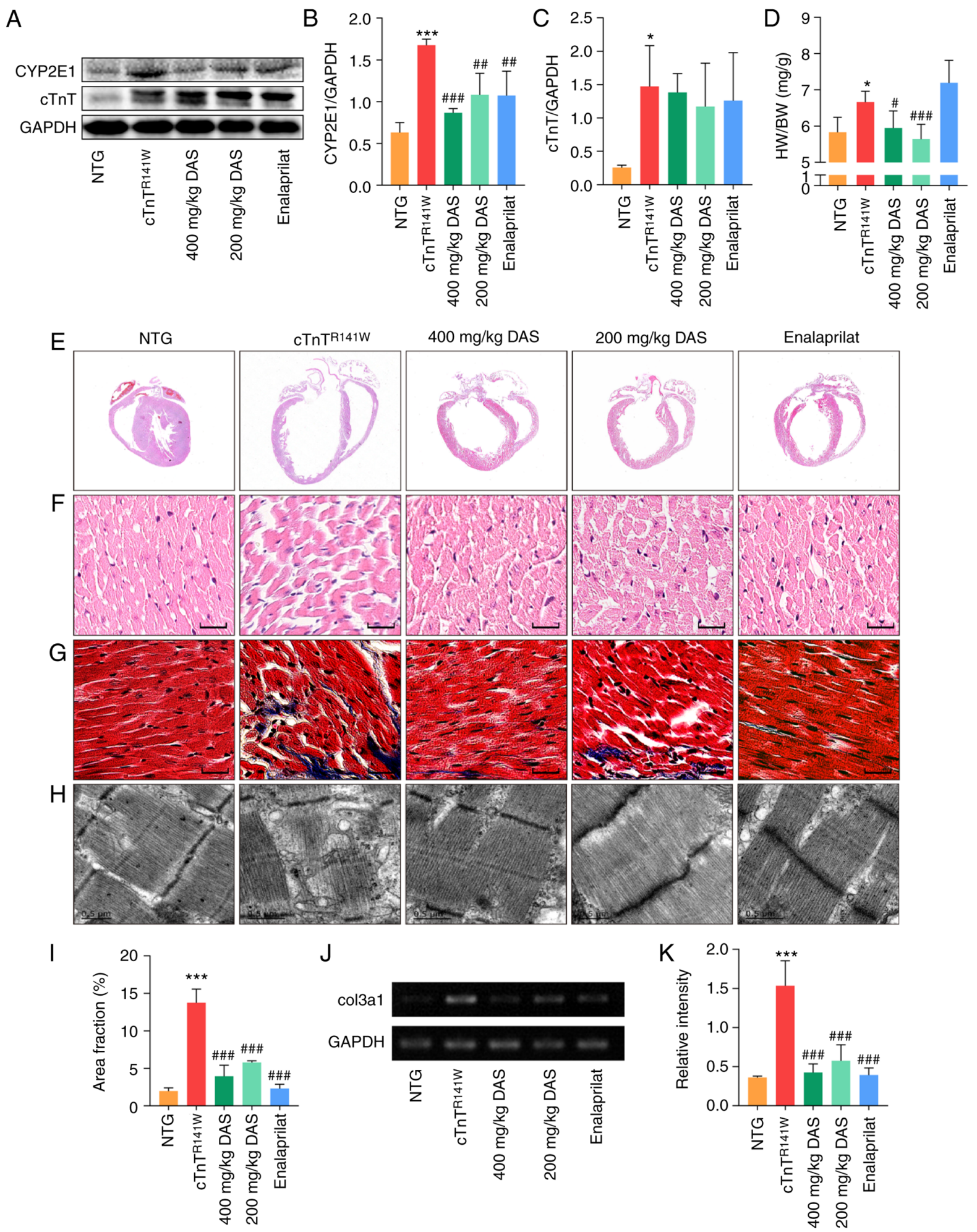

Figure 2. Pathological histology observation. (A) CYP2E1 and cTnT expression in the heart tissues of mice in the NTG, cTnT ${ }^{\mathrm{R} 141 \mathrm{w}}, 400,200 \mathrm{mg} / \mathrm{kg}$ DAS and enalaprilat groups was detected via western blotting. (B) CYP2E1 and (C) cTnT were semi-quantitatively analyzed, using GAPDH for normalization $(n=3)$. (D) Ratio of HW to BW (n=6). (E) H\&E staining patterns of whole-heart longitudinal sections. (F) Magnification of H\&E-stained sections of the left ventricle (magnification, x400; scale bar, $20 \mu \mathrm{m}$ ). (G) Magnification of Masson's trichrome-stained left ventricle sections (magnification, x400, scale bar, $20 \mu \mathrm{m}$ ). Myocytes are stained red; collagenous tissue is stained blue. (H) Ultrastructure observation via transmission electron microscopy (scale bar, $0.5 \mu \mathrm{m}$ ). (I) Quantitative analysis of Masson staining ( $\mathrm{n}=3)$. ( $\mathrm{J})$ Col3 $\alpha 1$ expression was detected and $(\mathrm{K})$ analyzed $(\mathrm{n}=3)$. ${ }^{*} \mathrm{P}<0.05,{ }^{* * * *} \mathrm{P}<0.001$ vs. NTG group; ${ }^{*} \mathrm{P}<0.05$, ${ }^{\# \prime} \mathrm{P}<0.01,{ }^{\# \# \#} \mathrm{P}<0.001$ vs. $\mathrm{cTnT}^{\mathrm{R} 141 \mathrm{~W}}$ mice. cTnT, cardiac troponin $\mathrm{T} ; \mathrm{HW}$, heart weight; BW, body weight; Col3 $\alpha 1$, procollagen type III $\alpha 1$; NTG, non-transgenic; DAS, diallyl sulfide; CYP2E1, cytochrome P450 family 2 subfamily E member 1.

DAS, as an active ingredient in garlic, it is less toxic than other garlic sulfides, such as diallyl disulfide and diallyl trisulfide. DAS can be rapidly metabolized into diallyl sulfoxide
(DASO), diallyl sulfone (DASO2) and allyl mercaptan. Allyl mercaptan is the decomposition product of DAS, and DASO and DASO2 are sulfur oxidation products of DAS. 

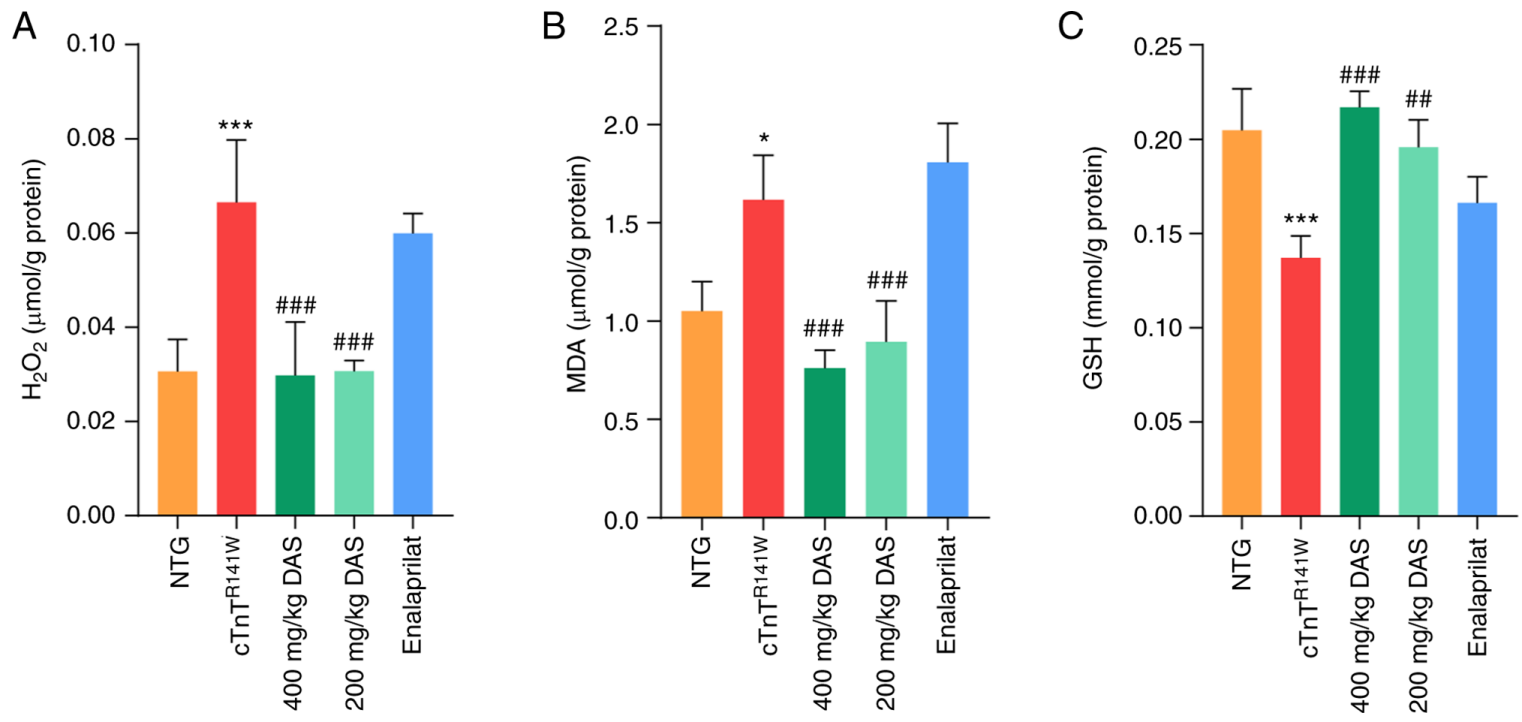

Figure 3. Determination of oxidative stress levels. Levels of (A) $\mathrm{H}_{2} \mathrm{O}_{2}$, (B) MDA and (C) GSH in the heart tissues of mice in the NTG, $\mathrm{cTnT}^{\mathrm{R} 141 \mathrm{w}}, 400,200 \mathrm{mg} / \mathrm{kg}$ DAS and enalaprilat groups were determined using colorimetric assays $(\mathrm{n}=3) .{ }^{*} \mathrm{P}<0.05,{ }^{* * * *} \mathrm{P}<0.001$ vs. NTG group; ${ }^{\# \#} \mathrm{P}<0.01,{ }^{\# \# \#} \mathrm{P}<0.001 \mathrm{vs}$. cTnT ${ }^{\mathrm{R} 141 \mathrm{~W}}$ mice. MDA, malondialdehyde; GSH, glutathione; NTG, non-transgenic; DAS, diallyl sulfide.

DASO and DASO2 are the main metabolites among DAS metabolites, and their formation is mediated by the CYP2E1 enzyme. DAS is both a selective inhibitor and a substrate of CYP2E1. Since sulfur is more nucleophilic than DAS terminal carbon, sulfur strongly binds to heme of CYP2E1, leading to competitive inhibition of CYP2E1 by DAS or metabolism into DASO $(18,47,48)$. DAS inhibits the metabolism of P-450 2E1 substrates via competitive inhibition mechanisms and by inactivating P-450 2E1 via a suicide-inhibitory action of DASO2 $(18,47,48)$.

$\mathrm{cTnT}^{\mathrm{R} 141 \mathrm{~W}}$ mice develop typical DCM phenotypes from 4 months of age, with death from HF after 8 months of age $(27,49)$. cTnT $^{\mathrm{R} 141 \mathrm{~W}}$ transgenic mice displayed typical familial dilated cardiomyopathy phenotypes with dilated chambers, thin walls and cardiac dysfunction, as well as pathological phenotypes with myocytes disarray and fibrosis $(4,26,27)$.

In the present study, it was identified that DAS treatment improved the DCM phenotypes of chamber dilation, wall thinning, myocyte disarray, fibrosis, poor myofibril organization and decreased ventricular blood ejection in $\mathrm{cTnT}^{\mathrm{R} 141 \mathrm{~W}}$ DCM model mice. Furthermore, DAS treatment inhibited ROS production and decreased cytochrome $c$ release, caspase 9-dependent caspase 3 activation, and thus, apoptosis of myocytes in $\mathrm{CTnT}^{\mathrm{R} 141 \mathrm{~W}} \mathrm{DCM}$ model mice.

The current results are in line with others. DAS analogues reduce the cytotoxicity associated with metabolism of alcohol, analgesics and xenobiotic by inhibiting CYP2E1 activity. In pathological conditions associated with CYP2E1 upregulation or CYP2E1-mediated adverse reactions (including diabetes/hyperlipidemia, Parkinson's disease, AIDS and cancer), DAS can reduce the damage caused by the pathological stimulus (18). DAS has been reported as a potentially effective intervention. The experimental results from previous studies have shown that DAS could not only inhibit ethanol and drug-mediated cytotoxicity, but also inhibit HIV proteinand diabetes-mediated toxicities by selectively inhibiting
CYP2E1 in various cell types $(18,50-53)$. In addition, the antioxidant/anti-inflammatory effects of DAS further support its use as dietary supplements (18). The current research, along with that of others, indicated that DAS could improve the symptoms of related diseases by targeting CYP2E1. In addition, the present study examined a NTG normal group with DAS treatment, and the heart structure and function of NTG group mice treated with DAS $(400 \mathrm{mg} / \mathrm{kg})$ did not shown abnormality in the echocardiography analysis (Table SIV). However, DAS, as a result of its rapid metabolism to DASO and DASO2, also causes cellular toxicity $(18,54)$. Therefore, there is a need to modify the parent DAS into an analogue, which is a stronger inhibitor, but a weaker substrate of CYP2E1 $(18,54)$.

Enalaprilat was selected in the present study to compare it with the therapeutic effect and characteristics of DAS. Enalaprilat is an ACE inhibitor that has been widely used in the clinical treatment of HF, including in patients with DCM $(33,34,55-57)$. Enalaprilat is characterized by difficulties in direct absorption in the gastrointestinal tract and low oral absorption, and in terms of renal clearance, there is a barrier to entry of enalaprilat into the kidneys (58-60). DAS, as an active ingredient of garlic, is less toxic than other sulfides in garlic. The characteristic of DAS includes its action specificity, rapid metabolic clearance and cytotoxicity; therefore, DAS can be chemically modified to adjust its cytotoxicity and metabolic clearance rate $(18,47,48)$.

In the present study, both of DAS and enalaprilat exhibited satisfactory inhibition on the pathological development of DCM in $\mathrm{cTnT}^{\mathrm{R} 141 \mathrm{~W}}$ mice; however, each has its own characteristics. DAS treatment showed advantages in improving cardiac function and chamber dilation in vivo, as evidenced by the changes in echocardiographic parameters of LVFS, LVEF, LVESD and LVEDD. Furthermore, this improvement was more pronounced in the early stage of the treatment in both DAS groups than in the enalaprilat group, according to the significance findings after 2, 4 and 6 weeks of treatment. However, enalaprilat treatment was more effective in improving the microstructure and ultrastructure 


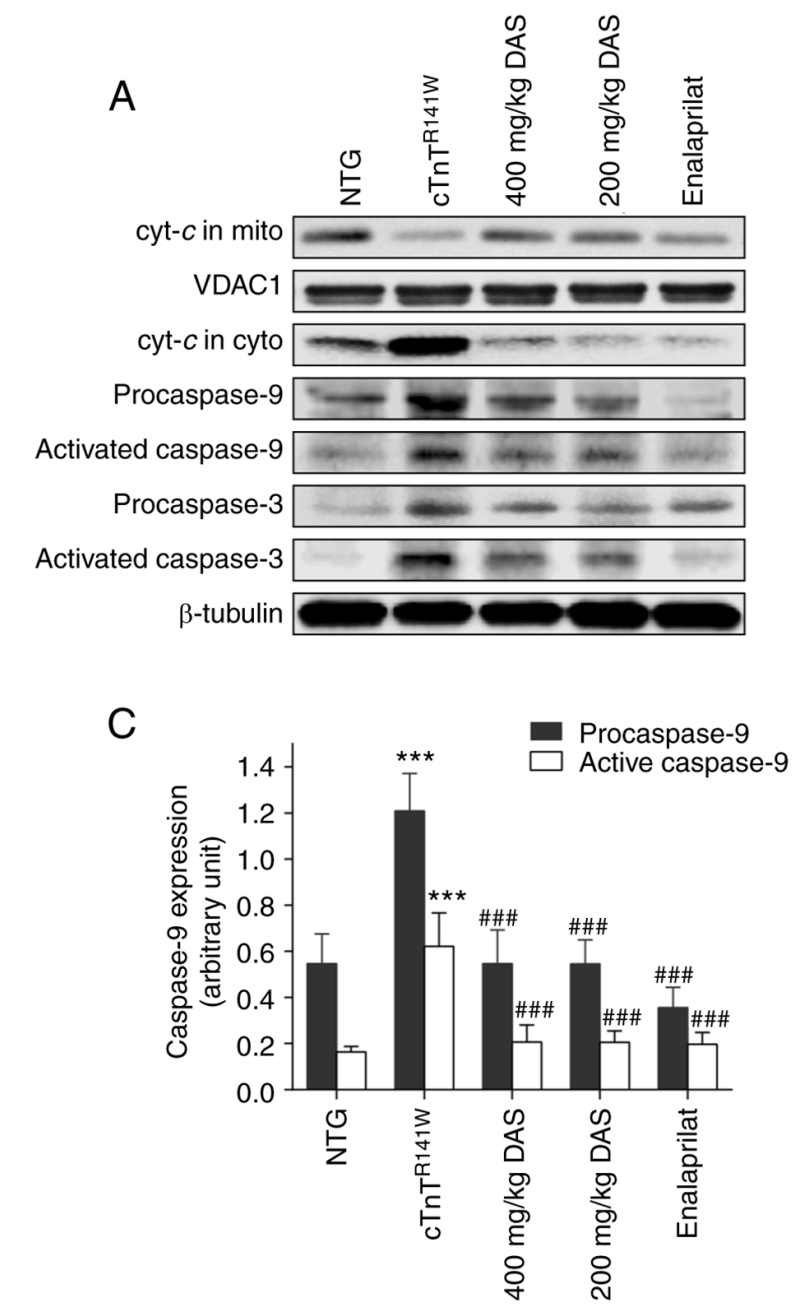

B

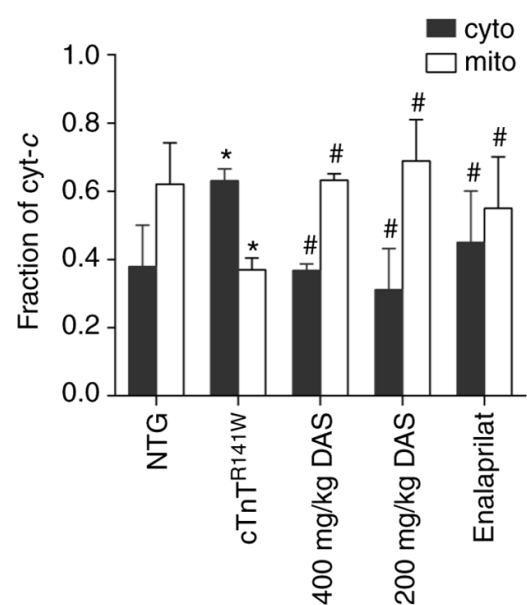

D

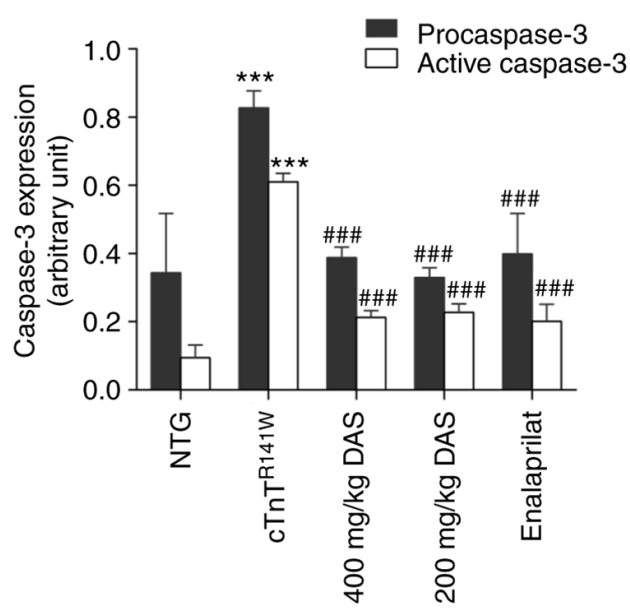

E
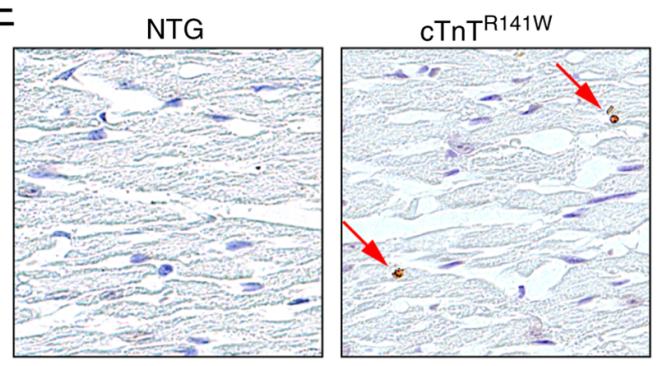

$400 \mathrm{mg} / \mathrm{kg}$ DAS

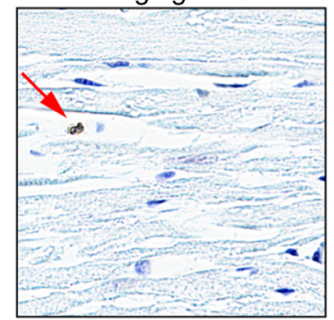

F

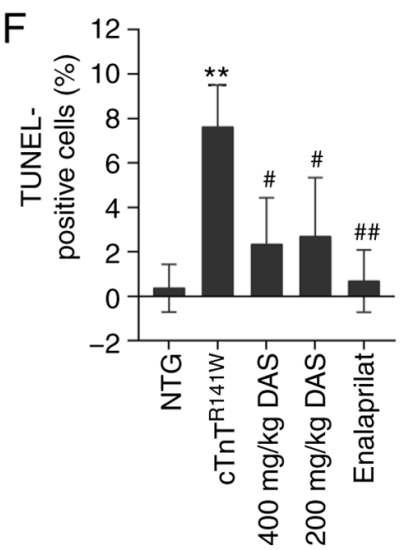

Figure 4. Analysis of the mitochondria-dependent apoptosis pathways. (A) Cyt-c release and activation of caspase 9 and caspase 3 in the heart tissues of mice in the NTG, cTnT ${ }^{\mathrm{R} 141 \mathrm{w}}, 400,200 \mathrm{mg} / \mathrm{kg}$ DAS and enalaprilat groups were detected via western blotting. (B) Cyt- $c$ in the cyto and mito was semi-quantitatively analyzed using $\beta$-tubulin or VDAC1 for normalization. (C) Procaspase 9 and (D) procaspase 3 and active caspases 3 and 9 were semi-quantitatively analyzed using $\beta$-tubulin for normalization ( $\mathrm{n}=3$ ). (E) Cardiac myocyte apoptosis was detected using a TUNEL assay, and the arrows indicate TUNEL-positive cells (magnification, $\mathrm{x} 400$ ). (F) Number of positive cells was counted, and the proportion of apoptotic cells among the total cells in each image was calculated (n=3). ${ }^{*} \mathrm{P}<0.05,{ }^{* *} \mathrm{P}<0.01,{ }^{* * *} \mathrm{P}<0.001$ vs. NTG group; ${ }^{\#} \mathrm{P}<0.05,{ }^{\# \#} \mathrm{P}<0.01,{ }^{\# \# \#} \mathrm{P}<0.001$ vs. cTnT ${ }^{\mathrm{R} 141 \mathrm{~W}}$ mice. Cyt $c$, Cytochrome $c$; cyto, cytoplasm; mito, mitochondria; VDAC1, voltage dependent anion channel 1; NTG, non-transgenic; DAS, diallyl sulfide. 
of myocardium. In terms of the mechanism of action, DAS, rather than enalaprilat, exhibited an improved inhibitory effect on controlling oxidative stress levels, using $\mathrm{H}_{2} \mathrm{O}_{2}$, MDA and GSH as indicators. Moreover, both of DAS and enalaprilat showed an excellent control effect on the mitochondrial apoptosis pathway.

The results of enalapril in improving oxidative stress are not satisfactory, and the exact mechanism remains unknown. However, it has been reported that MDA levels were not reduced in the enalapril-treated endothelial cells, while this treatment improved those of glutathione peroxidase and superoxide dismutase (61). This suggested that the specific indicators of enalaprilat in controlling oxidative stress are different from those detected in the present study, which may partly explain why the enalaprilat does not show a favorable control ability on improving MDA and other indicators of oxidative stress.

In addition, the current study selected a widely used myocardial cell line, H9c2, to verify the ameliorative effect of DAS on the pathological phenotype of cardiomyopathy in vitro. DAS could significantly inhibit the increased expression of CYP2E1 induced by ISO in H9c2 cells, and it also significantly improve the cell death induced by ISO, which were all consistent with the results in vivo.

According to previous research, underlying cellular processes, including inflammation and hypertrophy, myocyte apoptosis and necrosis, and deposition of extracellular matrix, have a direct association with the oxidative state of cardiac cells $(54,62)$. Garlic and its active ingredients (such as phenols and saponins) have antioxidant effect (63). DAS can improve the oxidative stress induced by thallium acetate (TI), reduce the increase of MDA and nitric oxide levels in serum and liver, the decrease of GSH and catalase activities in liver and the decrease of total antioxidant capacity caused by TI (64). DAS can oxidize and glycosylate low-density lipoprotein to prevent additional oxidation or deterioration of glycosylation, which may benefit patients with diabetes-related vascular disease (65). Garlic oil is a source of DAS, and studies reported that garlic oil could be recommended as an option for treating hypertrophic cardiovascular disease (66). Cardiovascular diseases involve serum total cholesterol, low-density lipoprotein oxidation, platelet aggregation and hypertension (66). In vitro studies have shown garlic-induced inhibition of lipid synthesis, platelet aggregation, erythrocyte lipid peroxidation and low-density lipoprotein oxidation (66).

A limitation of the current study was that the improvement of DAS occurred in the early stage of the treatment, while the effect did not last a sufficient duration in the DAS low dose group. Therefore, future work will examine the range of diseases that DAS could be applied, as well as develop structural analogues with a lower cytotoxicity and metabolic rate.

In conclusion, the present study demonstrated that DAS had advantages in terms of improved chamber dilation and increased ventricular blood ejection. Furthermore, the regulatory mechanisms underlying DAS involvement in the DCM pathological development, included inhibition of both the oxidative stress levels and the mitochondria-dependent apoptosis pathways.

\section{Acknowledgements}

The authors thank Dr Ya-jun Yang (Institute of Material Medical, Chinese Academy of Medical Sciences and Peking Union Medical College) for detection and analysis in the pharmacokinetic study.

\section{Funding}

The present work was supported by Chinese Academy of Medical Sciences Innovation Fund for Medical Sciences (grant no. 2016-I2M-1-015), National Natural Science Foundation of China (grant no. 31872314) and Beijing Natural Science Foundation (grant no. 5212017).

\section{Availability of data and materials}

The datasets used and/or analyzed during the current study are available from the corresponding author on reasonable request.

\section{Authors' contributions}

LZ conceived the experiments and wrote the paper. DL analyzed the data and wrote the paper. SP performed most of the experiments and analyzed the data, including echocardiography parameters analysis, pathological analysis, western blotting, biochemical analysis and immunohistochemical analysis. WD contributed to the echocardiography procedure. NL and SG contributed to the genotyping and animal breeding and management. JL contributed to the TEM analysis. XZ contributed to animal administration procedures and RT-PCR analysis. LZ and DL confirmed the authenticity of all the raw data. All authors read and approved the final version of the manuscript.

\section{Ethics approval and consent to participate}

All animal procedures were approved by the Animal Care and Use Committee at the Institute of Laboratory Animal Science, Peking Union Medical College (approval no. ZLF18004). All mice were bred in an AAALAC-accredited facility and animal experiments were carried out in accordance with animal welfare requirements and the Guidelines for the Care and Use of Laboratory Animals published by the Chinese Ministry of Health.

\section{Patient consent for publication}

Not applicable.

\section{Competing interests}

The authors declare that they have no competing interests.

\section{References}

1. Leung T, Rajendran R, Singh S, Garva R, Krstic-Demonacos M and Demonacos C: Cytochrome P450 2E1 (CYP2E1) regulates the response to oxidative stress and migration of breast cancer cells. Breast Cancer Res 15: R107, 2013. 
2. Sheng Y, Yang H, Wu T, Zhu L, Liu L and Liu X: Alterations of cytochrome P450s and UDP-glucuronosyltransferases in brain under diseases and their clinical significances. Front Pharmacol 12: 650027, 2021

3. Cederbaum AI: Alcohol metabolism. Clin Liver Dis 16: 667-685, 2012.

4. Lu D, Ma Y, Zhang W, Bao D, Dong W, Lian H, Huang L and Zhang L: Knockdown of cytochrome P450 2E1 inhibits oxidative stress and apoptosis in the cTnT(R141W) dilated cardiomyopathy transgenic mice. Hypertension 60: 81-89, 2012.

5. Murray B, Peng H, Barbier-Torres L, Robinson AE, Li TWH Fan W, Tomasi ML, Gottlieb RA, Van Eyk J, Lu Z, et al: Methionine adenosyltransferase $\alpha 1$ is targeted to the mitochondrial matrix and interacts with cytochrome P450 2E1 to lower its expression. Hepatology70: 2018-2034, 2019.

6. Harjumäki R, Pridgeon CS and Ingelman-Sundberg M: CYP2E1 in alcoholic and non-alcoholic liver injury. Roles of ROS, reactive intermediates and lipid overload. Int J Mol Sci 22: 8221, 2021.

7. Tomasi ML, Ramani K, Ryoo M, Cossu C, Floris A, Murray BJ, Iglesias-Ara A, Spissu Y and Mavila N: SUMOylation regulates cytochrome P450 2E1 expression and activity in alcoholic liver disease. FASEB J 32: 3278-3288, 2018.

8. Leung TM and Nieto N: CYP2E1 and oxidant stress in alcoholic and non-alcoholic fatty liver disease. J Hepatol 58: 395-398, 2013.

9. Schattenberg JM and Czaja MJ: Regulation of the effects of CYP2E1-induced oxidative stress by JNK signaling. Redox Biol 3: 7-15, 2014

10. Santra S, Bishnu D, Dhali GK, Santra A and Chowdhury A: Expression of type I collagen in response to isoniazid exposure is indirect and is facilitated by collateral induction of cytochrome P450 2E1: An in-vitro study. PLoS One 15: e0236992, 2020.

11. Kuzgun G, Başaran R, Arıŏglu İnan E and Can Eke B: Effects of insulin treatment on hepatic CYP1A1 and CYP2E1 activities and lipid peroxidation levels in streptozotocin-induced diabetic rats. J Diabetes Metab Disord 19: 1157-1164, 2020.

12. Paradies G, Paradies V, Ruggiero FM and Petrosillo G: Oxidative stress, cardiolipin and mitochondrial dysfunction in nonalcoholic fatty liver disease. World J Gastroenterol 20: 14205-14218, 2014.

13. Navarro-Mabarak C, Camacho-Carranza R and Espinosa-Aguirre JJ: Cytochrome P450 in the central nervous system as a therapeutic target in neurodegenerative diseases Drug Metab Rev 50: 95-108, 2018.

14. Baltazar MT, Dinis-Oliveira RJ, de Lourdes Bastos M, Tsatsakis AM, Duarte JA and Carvalho F: Pesticides exposure as etiological factors of Parkinson's disease and other neurodegenerative diseases-a mechanistic approach. Toxicol Lett 230: 85-103, 2014.

15. Abdelmegeed MA, Ha SK, Choi Y, Akbar M and Song BJ: Role of CYP2E1 in mitochondrial dysfunction and hepatic injury by alcohol and non-alcoholic substances. Curr Mol Pharmacol 10: 207-225, 2017

16. Yin X, Xiong W, Wang Y, Tang W, Xi W, Qian S and Guo Y: Association of CYP2E1 gene polymorphisms with bladder cancer risk: A systematic review and meta-analysis. Medicine (Baltimore) 97: e11910, 2018.

17. Martinez-Gil N, Vidal-Gil L, Flores-Bellver M, Maisto R, Sancho-Pelluz J, Diaz-Llopis M, M Barcia J and Romero FJ: Ethanol-induced oxidative stress modifies inflammation and angiogenesis biomarkers in retinal pigment epithelial cells (ARPE-19): Role of CYP2E1 and its inhibition by antioxidants. Antioxidants (Basel) 9: 776, 2020.

18. Rao PS, Midde NM, Miller DD, Chauhan S, Kumar A and Kumar S: Diallyl sulfide: Potential use in novel therapeutic interventions in alcohol, drugs, and disease mediated cellular toxicity by targeting cytochrome P450 2E1. Curr Drug Metab 16: 486-503, 2015.

19. Hong JY, Wang ZY, Smith TJ, Zhou S, Shi S, Pan J and Yang CS: Inhibitory effects of diallyl sulfide on the metabolism and tumorigenicity of the tobacco-specific carcinogen 4-(methylnit rosamino)-1-(3-pyridyl)-1-butanone (NNK) in A/J mouse lung. Carcinogenesis 13: 901-904, 1992.

20. Jin M, Ande A, Kumar A and Kumar S: Regulation of cytochrome P450 2el expression by ethanol: Role of oxidative stress-mediated pkc/jnk/sp1 pathway. Cell Death Dis 4: e554, 2013.

21. Morimoto M, Hagbjörk AL, Wan YJ, Fu PC, Clot P, Albano E Ingelman-Sundberg $M$ and French SW: Modulation of experimental alcohol-induced liver disease by cytochrome P450 2E1 inhibitors. Hepatology 21: 1610-1617, 1995.
22. Zhang RH, Gao JY, Guo HT, Scott GI, Eason AR, Wang XM and Ren J: Inhibition of CYP2E1 attenuates chronic alcohol intake-induced myocardial contractile dysfunction and apoptosis. Biochim Biophys Acta 1832: 128-141, 2013.

23. van Riet EE, Hoes AW, Wagenaar KP, Limburg A, Landman MA and Rutten FH: Epidemiology of heart failure: The prevalence of heart failure and ventricular dysfunction in older adults over time. A systematic review. Eur J Heart Fail 18: 242-252, 2016.

24. Shakib S and Clark RA: Heart failure pharmacotherapy and supports in the elderly-a short review. Curr Cardiol Rev 12: 180-185, 2016.

25. van der Pol A, van Gilst WH, Voors AA and van der Meer P: Treating oxidative stress in heart failure: Past, present and future. Eur J Heart Fail 21: 425-435, 2019

26. Zhang W, Lu D, Dong W, Zhang L, Zhang X, Quan X, Ma C, Lian $\mathrm{H}$ and Zhang L: Expression of CYP2E1 increases oxidative stress and induces apoptosis of cardiomyocytes in transgenic mice. FEBS J 278: 1484-1492, 2011.

27. Guan F, Yang X, Li J, Dong W, Zhang X, Liu N, Gao S, Wang J, Zhang L and Lu D: New molecular mechanism underlying Myc-mediated cytochrome P450 2E1 upregulation in apoptosis and energy metabolism in the myocardium. J Am Heart Assoc 8: e009871,2019.

28. Westphal C, Konkel A and Schunck WH: Cytochrome p450 enzymes in the bioactivation of polyunsaturated Fatty acids and their role in cardiovascular disease. Adv Exp Med Biol 851: 151-187, 2015.

29. Thum T and Borlak J: Cytochrome P450 mono-oxygenase gene expression and protein activity in cultures of adult cardiomyocytes of the rat. Br J Pharmacol 130: 1745-1752, 2000.

30. Aberle NS II and Ren J: Short-term acetaldehyde exposure depresses ventricular myocyte contraction: Role of cytochrome P450 oxidase, xanthine oxidase, and lipid peroxidation. Alcohol Clin Exp Res 27: 577-583, 2003.

31. Sidorik L, Kyyamova R, Bobyk V, Kapustian L, Rozhko O, Vigontina O, Ryabenko D, Danko I, Maksymchuk O, Kovalenko VN, et al: Molecular chaperone, HSP60, and cytochrome P450 2E1 co-expression in dilated cardiomyopathy. Cell Biol Int 29: 51-55, 2005.

32. Jing L, Jin CM, Li SS, Zhang FM, Yuan L, Li WM, Sang Y, Li S and Zhou LJ: Chronic alcohol intake-induced oxidative stress and apoptosis: Role of CYP2E1 and calpain-1 in alcoholic cardiomyopathy. Mol Cell Biochem 359: 283-292, 2012.

33. Kobaladze N, Tsibadze T, Iakobashvili M and Tabidze G: Angiotensin-converting enzyme inhibitor treatment of heart failure due to dilated cardiomyopathy. Georgian Med News: 41-44, 2005 (In Russian).

34. Cernecka H, Ochodnicka-Mackovicova K, Kucerova D, Kmecova J, Nemcekova V, Doka G, Kyselovic J, Krenek P, Ochodnicky P and Klimas J: Enalaprilat increases PPAR $\beta / \delta$ expression, without influence on PPAR $\alpha$ and PPAR $\gamma$, and modulate cardiac function in sub-acute model of daunorubicin-induced cardiomyopathy. Eur J Pharmacol 714: 472-477, 2013.

35. Salminen WF Jr, Roberts SM, Pumford NR and Hinson JA: Immunochemical comparison of 3'-hydroxyacetanilide and acetaminophen binding in mouse liver. Drug Metab Dispos 26: 267-271, 1998.

36. Saldaña-Ruíz S, Boadas-Vaello P, Sedó-Cabezón L and Llorens J: Reduced systemic toxicity and preserved vestibular toxicity following co-treatment with nitriles and CYP2E1 inhibitors: A mouse model for hair cell loss. J Assoc Res Otolaryngol 14: 661-671, 2013.

37. Cederbaum AI, Wu D, Mari M and Bai J: CYP2E1-dependent toxicity and oxidative stress in HepG2 cells. Free Radic Biol Med 31: 1539-1543, 2001.

38. Wollert KC, Heineke J, Westermann J, Lüdde M, Fiedler B, Zierhut W, Laurent D, Bauer MK, Schulze-Osthoff K and Drexler H: The cardiac Fas (APO-1/CD95) receptor/Fas ligand system: Relation to diastolic wall stress in volume-overload hypertrophy in vivo and activation of the transcription factor AP-1 in cardiac myocytes. Circulation 101: 1172-1178, 2000.

39. Yaniv G, Shilkrut M, Lotan R, Berke G, Larisch S and Binah O: Hypoxia predisposes neonatal rat ventricular myocytes to apoptosis induced by activation of the Fas (CD95/Apo-1) receptor: Fas activation and apoptosis in hypoxic myocytes. Cardiovasc Res 54: 611-623, 2002.

40. Thomson $\mathrm{M}$ and Ali M: Garlic (Allium sativum): A review of its potential use as an anti-cancer agent. Curr Cancer Drug Targets 3: 67-81, 2003 .

41. Nicastro HL, Ross SA and Milner JA: Garlic and onions: Their cancer prevention properties. Cancer Prev Res (Phila) 8: 181-189, 2015. 
42. McCaskill ML, Rogan E and Thomas RD: Diallyl sulfide inhibits diethylstilbestrol induced DNA damage in human breast epithelial cells (MCF-10A). Steroids 92: 96-100, 2014.

43. Begriche K, Knockaert L, Massart J, Robin MA and Fromenty B: Mitochondrial dysfunction in nonalcoholic steatohepatitis (NASH): Are there drugs able to improve it? Drug Discov Today Dis Mech 6: e11-e23, 2009.

44. Louvet A and Mathurin P: Alcoholic liver disease: Mechanisms of injury and targeted treatment. Nat Rev Gastroenterol Hepatol 12: 231-242, 2015.

45. Starley BQ, Calcagno CJ and Harrison SA: Nonalcoholic fatty liver disease and hepatocellular carcinoma: A weighty connection. Hepatology 51: 1820-1832, 2010.

46. Wieckowska A, McCullough AJ and Feldstein AE: Noninvasive diagnosis and monitoring of nonalcoholic steatohepatitis: Present and future. Hepatology 46: 582-589, 2007.

47. Brady JF, Ishizaki H, Fukuto JM, Lin MC, Fadel A, Gapac JM and Yang CS: Inhibition of cytochrome P-450 2E1 by diallyl sulfide and its metabolites. Chem Res Toxicol 4: 642-647, 1991.

48. Brady JF, Wang MH, Hong JY, Xiao F, Li Y, Yoo JS, Ning SM Lee MJ, Fukuto JM, Gapac JM, et al: Modulation of rat hepatic microsomal monooxygenase enzymes and cytotoxicity by diallyl sulfide. Toxicol Appl Pharmacol 108: 342-354, 1991.

49. Tayal U, Prasad S and Cook SA: Genetics and genomics of dilated cardiomyopathy and systolic heart failure. Genome Med 9: 20, 2017.

50. Wu D and Cederbaum AI: Cyclosporine A protects against arachidonic acid toxicity in rat hepatocytes: Role of CYP2E1 and mitochondria. Hepatology 35: 1420-1430, 2002.

51. Dai Y and Cederbaum AI: Cytotoxicity of acetaminophen in human cytochrome P4502E1-transfected HepG2 cells. J Pharmacol Exp Ther 273: 1497-1505, 1995.

52. Isaguliants M, Smirnova O, Ivanov AV, Kilpelainen A, Kuzmenko Y, Petkov S, Latanova A, Krotova O, Engström G, Karpov V, et al: Oxidative stress induced by HIV-1 reverse transcriptase modulates the enzyme's performance in gene immunization. Hum Vaccin Immunother 9: 2111-2119, 2013.

53. Swaminathan K, Kumar SM, Clemens DL and Dey A: Inhibition of CYP2E1 leads to decreased advanced glycated end product formation in high glucose treated ADH and CYP2E1 over-expressing VL-17A cells. Biochim Biophys Acta 1830: 4407-4416, 2013.

54. Jin L and Baillie TA: Metabolism of the chemoprotective agent diallyl sulfide to glutathione conjugates in rats. Chem Res Toxicol 10: 318-327, 1997.
55. Travessa AM and Menezes Falcão L: Vasodilators in acute heart failure-evidence based on new studies. Eur J Intern Med 51: 1-10, 2018.

56. Momma K: ACE inhibitors in pediatric patients with heart failure. Paediatr Drugs 8: 55-69, 2006.

57. Smeets NJL, Schreuder MF, Dalinghaus M, Male C, Lagler FB, Walsh J, Laer S and de Wildt SN: Pharmacology of enalapril in children: A review. Drug Discov Today: Aug 21, 2020 (Epub ahead of print)

58. de Lannoy IA, Nespeca R and Pang KS: Renal handling of enalapril and enalaprilat: Studies in the isolated red blood cell-perfused rat kidney. J Pharmacol Exp Ther 251: 1211-1222, 1989.

59. Tocco DJ, deLuna FA, Duncan AE, Vassil TC and Ulm EH: The physiological disposition and metabolism of enalapril maleate in laboratory animals. Drug Metab Dispos 10: 15-19, 1982.

60. Gross DM, Sweet CS, Ulm EH, Backlund EP, Morris AA, Weitz D, Bohn DL, Wenger HC, Vassil TC and Stone CA: Effect of N-[(S)-1-carboxy-3-phenylpropyl]-L-Ala-L-Pro and its ethyl ester (MK-421) on angiotensin converting enzyme in vitro and angiotensin I pressor responses in vivo. J Pharmacol Exp Ther 216: 552-557, 1981 .

61. Mailloux A, Deslandes B, Vaubourdolle M and Baudin B: Captopril and enalaprilat decrease antioxidant defences in human endothelial cells and are unable to protect against apoptosis. Cell Biol Int 27: 825-830, 2003.

62. Hantson P: Mechanisms of toxic cardiomyopathy. Clin Toxicol (Phila) 57: 1-9, 2019.

63. Shang A, Cao SY, Xu XY, Gan RY, Tang GY, Corke H, Mavumengwana V and Li HB: Bioactive compounds and biological functions of garlic (Allium sativum L.). Foods 8: 246, 2019.

64. Abdel-Daim MM and Abdou RH: Protective effects of diallyl sulfide and curcumin separately against thallium-induced toxicity in rats. Cell J 17: 379-388, 2015.

65. Huang CN, Horng JS and Yin MC: Antioxidative and antiglycative effects of six organosulfur compounds in low-density lipoprotein and plasma. J Agric Food Chem 52: 3674-3678, 2004.

66. Suman S and Shukla Y: Diallyl sulfide and its role in chronic diseases prevention. Adv Exp Med Biol 929: 127-144, 2016.

This work is licensed under a Creative Commons Attribution-NonCommercial-NoDerivatives 4.0 International (CC BY-NC-ND 4.0) License. 